\title{
Maurice Blanchot e a exigência fragmentária
}

Elisabete Marques

Centro de Estudos Comparatistas

Universidade de Lisboa - Portugal

\begin{abstract}
Resumo
Este ensaio debruça-se sobre a "exigência fragmentária", tal como a concebeu Maurice Blanchot. Esta não se daria como característica formal de textos, na forma de pequenos blocos fechados de sentido, distinguindo-se, portanto, do "fragmento" romântico, ainda sob a dependência da noção de "unidade", conforme a definiçấo de Schlegel. O que se encontra em causa na escrita fragmentária são as relaçôes entre elementos singulares, relaçôes essas que imprimem ritmo e que, configurando novas possibilidades de sentido, extravasam o "todo". Nessa medida, e porque a criação de ligaçôes também depende dela, tratar-se-á igualmente de considerar a leitura como gesto de reescrita que, mantendo o texto incólume, transforma-o sempre noutro. O jogo desta escrita fragmentária subentende uma comunidade de leitores por vir e em aberto (inconfessável), e indicia também uma hipotética relação com o "fora".
\end{abstract}

Palavras-chave: Blanchot; fragmento; fragmentário; escrita; leitura.

\begin{abstract}
This essay focuses on the "fragmentary imperative", as developed by Maurice Blanchot. This imperative does not consist in a merely formal characteristic of texts of a certain kind. It is therefore to be distinguished from the romantic "fragment", as defined by Schlegel, which still depends on the notion of "unity". At issue in fragmentary writing are the relationships between the singular elements of a text, which provide it with its proper rhythm and, by way of creating new meanings, somehow spill the "whole". In that sense, we need to rethink reading, since the invention of different textual relations depends on it. We will discuss that reading is an act of rewriting, which paradoxically transforms the text, while keeping it unscathed. The play of fragmentary writing presupposes an open community of readers, and, in doing so, it evidences a possible relation with the "outside".
\end{abstract}

Keywords: Blanchot; fragment; fragmentary; writing; reading. 
1. Entender-se-á este itálico se se atender às dificuldades acarretadas por tal atributo. Neste texto, defenderemos que qualquer exercício de resposta aos textos, na medida em que é pensamento, se dá sempre como ensaio, experimentação.

A ideia do ensaio, a nosso ver, não se restringe a uma forma textual institucionalizada, canónica. A este propósito leia-se o texto de Silvina Rodrigues Lopes, "Do Ensaio como pensamento experimental”, 2003.

2. Considere-se a estrutura e o movimento interno de L'Entretien Infini, 1969, ou, nas obras posteriores, a adopção formal do fragmento, Le Pas au-delà, 1973, e L'Écriture du desastre, 1980, por exemplo.

3. Leslie Hill, em Maurice Blanchot and the fragmentary writing, 2012, parece encontrar uma viragem desde os anos 50 na produção textual blanchotiana. Seria a partir dessa altura que Blanchot teria pensado com maior acuidade a questão da fragmentariedade. Hill associa tal alteração à ideia de "changement d'époche" (expressão de Blanchot), sendo que "época" não se esgotaria na etimologia, a que diz respeito à ruptura num tempo (que, no caso, poderia associar-se à experiência pós-campos concentracionários), mas relacionar-se-ia igualmente com a epoché fenomenológica enquanto método de pensamento que implica a suspensão (do juízo). Este livro procura esclarecer as diferentes leituras (Hegel, Schlegel, Novalis, Nietzsche, Husserl, Heidegger, Lévinas, Bataille, Derrida) de Blanchot e as reinvenções acarretadas por elas que suscitarão a questão da exigência fragmentária enquanto princípio da diferença, da disseminação, da não totalização. Importa também assinalar o facto de o mesmo autor trabalhar a ideia de "escrita do desastre" em correlação com tal ideia de suspensão. O rigoroso estudo de Hill acompanhar-nos-á, portanto, ao longo de todo o capítulo e por isso desde logo o referimos.
Il ne se délimite plus, il se fragmente.

Maurice Blanchot

Neste texto, procuraremos pensar o que possa ser a exigência fragmentária, atendendo às suas subtilezas, nomeadamente ao facto de se distinguir da forma do fragmento, e determinando a par e passo as razóes e consequências dessa distinção. Consideraremos o facto de Blanchot tematizar tal questão em vários textos de índole ensaística ${ }^{1}$, nos quais, não raras vezes, estilhaça a própria lei do género ${ }^{2}$, abrindo assim espaço para as mais diversas leituras. No nosso entender e conforme procuraremos mostrar, a fragmentariedade é a condiçâo da sobrevida dos textos. Ela diz respeito ao jogo escrita/leitura, pelo qual o texto se faz e desfaz. Por esse mesmo motivo, o fragmentário prova que nenhum texto é uma unidade fechada. Ele constitui-se também pelo que é a sua exterioridade, o fora. Veremos como estas questóes podem auxiliar-nos na meditação sobre a comunidade "inconfessável”. Para iniciar então a reflexão proposta, será necessário proceder à apreciação dos termos segundo os quais Blanchot medita nesta, como lhe chamou, exigência: exigência da escrita fragmentária. Comecemos, pois.

Antes de L'Entretien Infini (publicado em 1969), obra na qual o autor menciona explicitamente o fragmentário, deve notar-se a emergência da questão na produção textual de Blanchot. Para tal, basta atender à cadência sincopada e à forma estilhaçada de L'Attente l'oubli e considerar por exemplo os ensaios que escreveu sobre Blaise Pascal, Friedrich Nietzsche, René Char, Stéphane Mallarmé, Franz Kafka ou Edmond Jabés, reunidos em La Part du feu, como que implicitamente apontando para a questão. Não esqueçamos todavia, conforme dissemos, que ela ganha protagonismo em 1969, náo sendo esta data, segundo a leitura de Eric Hoppenot, em nada casual ${ }^{3}$. Para o comentador, ela coincidiria com o momento em que algumas preocupaçóes políticas de Blanchot se teriam tornado proeminentes:

La décision de s'engager dans l'écriture fragmentaire va de pair avec un souci, qui est de renouer dans la décennie 5868 avec une "activité " politique et mondaine, activité qu'il avait abandonnée depuis la guerre. Ce n'est pas l'engagement en tant que tel qui conduit Blanchot vers le fragmentaire mais le mode d'expression de cet engagement ; d'une part l'écriture collective de ce que l'on nommera le "Manifeste des 121 " et d'autre part l'écriture d'une revue consécutive au Manifeste. Cet appel à l'insoumission, revendiquée, assumée jusqu'à l'inculpation de ses signataires, provoque un immense remous intellectuel. Sartre avait déclaré à Blanchot que l'engagement du "Manifeste des 121 " n'aurait de sens que s'il était poursuivi par une revue faisant écho au nouveau climat intellectuel. Pour Blanchot, il signifie qu'il faut maintenant écrire autrement ; il y a eu une brisure, une interrup- 
tion de l'Histoire qui implique un changement radical du mode d'expression de l'intellectuel, ce bouleversement doit $s^{\prime}$ incarner dans une écriture collective. ${ }^{4}$

A escrita fragmentária corresponderia, nessa medida, diz-nos Hoppenot, a um imperativo, a uma necessidade política, inscrevendo uma ruptura na Estética (como disciplina), mas igualmente na concepção do próprio tempo. $\mathrm{O}$ fragmentário corresponderia, como tal, a "um outro tempo" - para Hoppenot, "a ausência de tempo" conforme surge em L'Espace Littéraire -, relacionável com alguns eventos históricos (a guerra, a Shoah). Lembremos a esse propósito, porém, a pequena resposta de Blanchot a um inquérito feito por uma revista polaca sobre a influência da guerra na literatura, "Guerre et littérature", em L'Amitié:

Le changement que subit le concept de littérature et qu'en France les tentatives marquées par les noms de "nouveau roman", "nouvelle critique", "structuralisme" ont servi à rendre spectaculaire, n'est pas en rapport immédiat avec la "deuxième guerre mondiale", étant en devenir depuis bien longtemps, mais y a trouvé la confirmation accélérée de la crise fondamental, changement d'époque que nous ne savons pas encore mesurer, faute d'un langage. Ce qui revient à dire : dans la crise qui ne cesse de s'approfondir et qui porte aussi la littérature selon son mode, la guerre est toujours présente et, d'une certaine manière, se poursuit.

Notemos a diferença entre a perspectiva blanchotiana segundo a qual a guerra teria agudizado a crise (qual?) já em curso na literatura, e a proposta de Hoppenot segundo a qual o fragmentário (e uma mudança de épocalépoché) resultaria da apreciação das crises históricas. Diferença subtil, contudo importante, uma vez que Blanchot sublinha, precisamente, a condição crítica da própria literatura, condição que podemos considerar a partir da perspectiva do Romantismo ${ }^{6}$ - e veremos como este se revela fulcral para Blanchot. De qualquer modo, e pondo de parte as oscilaçôes de sentido, importa assinalar a relação estreita entre a exigência fragmentária e as temporalidades da escrita/ leitura. Devemos, por isso, guardar na linha do nosso horizonte a observação de Hoppenot segundo a qual a própria enunciação e a experiência (literária) do tempo se encontram em crise no movimento do fragmentário e a compreensão de que tal circunstância tem, ainda que subtilmente, uma dimensão política.

Antes de desenvolvermos mais esta problemática, façamos algumas ressalvas, a todos os títulos determinantes. Esclareçamos, desde logo, que o fragmentário (pós-romântico), sendo, para Blanchot, um modo de pensar a literatura, se distingue do estudo do fragmento - embora mantendo com ele afinidades. Não se trataria pois de apreciar uma forma, um estilo, um gé-
4. HOPPENOT, Éric.

"Maurice Blanchot et l'écriture fragmentaire: 'le temps de l'absence de temps"', 2001, p. 364-365.

5. BLANCHOT, Maurice. "Guerre et littérature", 2010, p.128.

6. A este respeito, leia-se o capítulo "The philosophy of critique and the critique of philosophy: Romantic literary theory" de From Romanticism to critical theory, de Andrew Bowie, 1997. 
7. Walter Benjamin é a nosso ver o autor que melhor entende toda a dinâmica do fragmento romântico - identificando o movimento dialógico entre o fragmento como "mónada" e a "obra de arte total" (Gesamtkunstwerk), isto é, uma ideia de arte absoluta -, e as suas implicações na elaboração da concepção de uma crítica imanente. Remetemos por isso para a sua obra seminal O Conceito de crítica de Arte no Romantismo alemão, 1993. Do mesmo modo parece-nos útil a leitura dos primeiros capítulos do livro de Gilloch, Walter Benjamin - Critical Constellations, 2002, já que apresenta com clareza os movimentos da análise e da conceptualização benjaminianas.

8. Não estará L'Arrêt de mort de acordo com esta descrição? nero, um tema, uma técnica de escrita, nem táo-pouco de considerar o fragmento à luz das concepçóes românticas, em rigor, do chamado primeiro Romantismo alemáo ou Romantismo de Iena, segundo as quais o fragmento é já uma unidade de texto, fechada sobre si, como um ouriço ${ }^{7}$. A exigência fragmentária em questáo, tal como perspectivada por Blanchot, diria antes respeito ao facto de cada texto, na sua singularidade também idiomática, isto é, no seu acontecimento particular na escrita e na leitura, supor a interrupção da continuidade indiferenciada, ou, se quisermos, uma ruptura (mínima) na fala ininterrupta. Em L'Espace Littéraire, onde meditará diversas vezes acerca da interrupçáo e do désoeuvrement, aludindo, portanto, já ao fragmentário, o autor afirmará a necessidade premente do escritor/ leitor impor um silêncio momentâneo à fala continuada (um rumor, um murmúrio encerrado na própria palavra quotidiana) para poder fazer a obra, desde logo destinada à sua dissipação/ diluição.

Como Orfeu, o escritor deveria ser capaz de descer às profundezas da morte ou da noite para trazer Eurídice, silhueta obscura, à luz do dia. Para melhor compreender o alcance da imagem, convirá determo-nos brevemente no mito enunciado, reflectindo um pouco sobre os seus contornos. Relembremos: Orfeu teria de trazer a sombra de Eurídice até à claridade, para lhe dar forma, figura e realidade mas, para que fosse bem sucedido na sua missão, não a poderia olhar enquanto não saísse dos infernos. Para se aproximar dela estaria obrigado, pois, a desviar-se; para se avizinhar estaria obrigado a afastar-se. Porém, quebrando a lei imposta, Orfeu arruína a sua própria obra. Cabe portanto perguntar: por que é que Orfeu pôe tudo a perder, tentando vislumbrar Eurídice antes de chegar à superfície? Segundo Blanchot - e estamos já há algumas linhas a parafrasear "Le Regard d'Orphée" (primeiramente publicado em 1953), incluído em L'Espace littéraire -, o seu desejo por Eurídice como sombra é maior do que o desejo manifestado pela Eurídice diurna, agradavelmente quotidiana e familiar. Orfeu desejaria a obscuridade nocturna, a distância, o corpo fechado, a estranheza de Eurídice, sentindo-se precisamente compelido a vê-la quando e porque invisível; desejaria ele, acrescenta o autor, contemplar nela viva a plenitude da morte, mais do que, propriamente, fazê-la viver ${ }^{8}$. Teria sido essa, na verdade, a razão louca pela qual Orfeu descera aos Infernos. O poeta teria então perdido Eurídice porque a desejara para lá dos limites comedidos do canto, e, assim, ter-se-ia perdido a si mesmo, destroçado que fica - lembremo-nos de que será, finalmente, despedaçado pelas Mênades. Segundo Blanchot, as duas perdas são todavia necessárias ao canto, como à obra é necessário o désoeuvrement, a dissipação. Porquê?

Eis o diagnóstico de Blanchot: o erro de Orfeu teria sido o de querer "esgotar o infinito". Tendo esquecido a lei que the 
permitiria levar a bom termo a sua obra por impaciência ou, melhor, por inspiração e por desejo: Orfeu atraiçoara a sua obra e tarefa pelo desejo de e a favor da sombra, num gesto de pura irresponsabilidade diante da lei (instituída para cumprimento da obra). O olhar de Orfeu rompe então com os limites, estilhaça a lei que encerraria a essência e, por conseguinte, coincide com o momento da liberdade extrema: liberta-se Orfeu de si mesmo, e mais importante, liberta-se a obra do seu desígnio e autoridade. Extrapolando, diz Blanchot que tudo se joga, para quem escreve, para quem pensa, na decisão do olhar, pelo qual se interrompe o incessante. $\mathrm{O}$ desejo, a impaciência (da paciência), a despreocupaçáo, o salto seriam necessários à obra, pois seriam os modos pelos quais ela se liberta da sua própria lei. Conseguimos intuir em que medida a falha ou o désoeuvrement (constituindo este a quebra com a lei da obra), se aproxima da exigência fragmentária. Estilhaçada a lei da obra, esta, embora em aparência incólume (como volume, livro, obra-prima), só pode dar-se dissipando-se. Para Fernando Guerreiro, no ponto 14 da sua introdução ao livro de Patrícia San-Payo, Blanchot, a possibilidade da literatura: "Dés/oeuvrement refere não só um princípio de desactivação, inércia, interno à obra mas também a sua destruição a partir de si mesma. Mantendo-a assim aberta à possibilidade de ser 'outramente'" 9 . Não se trata de ser de outro modo, mas "de outro modo que ser", acrescentaremos em tom levinasiano ${ }^{10}$, já que a expressão é adoptada por Blanchot em Écriture du désastre ${ }^{11}$. Nessa medida, a exigência fragmentária suporia, finalmente, o descentramento da obra (ou o "centro descentrado") e a falha, ou seja, o neutro enquanto "princípio de inércia" e o désoeuvrement, implosão/explosão da lei da obra. Daí resultaria, de resto, a possibilidade de criar sentidos dinâmicos, a "palavra plural", e o "outramente" que ser da obra, desfazendo-se assim o domínio do onto-gnoseológico.

A irredutibilidade da exigência fragmentária blanchotiana à questão do fragmento tal como concebido pelo primeiro romantismo alemão remonta precisamente à questão do "outramente que ser" (o para além da essência, como ainda lemos no título de Lévinas). Blanchot distingui-los-á num texto de L'Entretien Infini, "L’Atheneaum", onde primeiro destacará a importância da revolução romântica:

[...] l'une des tâches du romantisme n'ait été d'introduire un mode tout nouveau d'accomplissement et même une véritable conversion de l'écriture: le pouvoir, pour l'œuvre, d'être et non plus de représenter, d'être tout, mais sans contenus ou avec des contenus presque indifférents et ainsi d'affirmer ensemble l'absolu et le fragmentaire, la totalité, mais dans une forme qui, étant toutes les formes, c'est-àdire à la limite n'étant aucune, ne réalise pas le tout, mais le signifie en le suspendant, voire en le brisant. ${ }^{12}$
9. GUERREIRO, Fernando.

"Notas sobre este livro", 2003, p. 12.

10. Tal expressão, que intitula o livro de Lévinas publicado em 1974, Autrement qu'être ou au-delà de l'essence, alude certamente a uma forma alternativa à da plenitude do ser. Apoiando-se na transcendência do diálogo subjectivo tal como Platão a entende, Lévinas entende a filosofia como agudamente vinculada à tensão entre o pensamento do ser e a questão do Outro. Dada a tendência da Ontologia a reduzir o Outro aos limites do Mesmo, Lévinas vê-a enquanto filosofia do poder e da egologia, e propõe em contrapartida que se tome a Ética como filosofia primeira. A fenomenologia do olhar é substituída pela da escuta, uma vez que o olhar ainda procuraria uma relação de adequação. A palavra transcenderia a visão. O Infinito é ruptura com a totalidade, desejo do absolutamente outro. A transcendência (como ética) para o filósofo dar-se-ia então a partir do desejo, da bondade e da inadequação. A Metafísica, para Lévinas, é justamente essa relação do Mesmo com o Outro, processando-se como discurso, todavia, sem formar totalidade, resistindo à sintetização operada pelo entendimento. Ela transgrediria assim a fenomenalidade, o mundo e sua luz, dando conta de uma opacidade. Talvez encontremos aqui algumas afinidades com $\mathrm{La}$ Folie du jour de Blanchot, embora, evidentemente, não possa este ser subsumido e reduzido a uma reflexão filosófica.
11. BLANCHOT, Maurice. L'Écriture du desastre, 2006, p. 138.

12. Idem. L'Entretien Infini, 2009, p. 518. 
13. A propósito deste assunto, é imprescindível referir o livro de Philippe Lacoue-Labarthe e Jean-Luc Nancy, L'Absolu littéraire, théorie de la littérature du romantisme allemand, 2010.

Veja-se particularmente, e de acordo com a discussão aqui desdobrada, o capítulo "L'exigence fragmentaire".

14. Leia-se a este respeito o artigo de Évelyne Grossman, "L'impensable, la pensée", 2003.

A autora parte dos dois artigos de Blanchot (um encontra-se em Le Livre à venir e o outro em L'Entretien Infini) sobre

Antonin Artaud para dar conta do espaço do pensamento ali evocado. Nos artigos de Blanchot, há uma incidência muito aguda sobre algumas passagens decisivas das cartas de Artaud a Jacques Rivière, nas quais o escritor partilha uma experiência do impoder, do vazio e da dissolução no movimento do pensar, ou seja, o escritor sente uma permanente sensação de falha ou de lacuna (de si próprio e do próprio pensamento). Segundo Grossman, Artaud dá conta de uma dimensão pré-subjectiva ou pré-egológica do pensamento; para além disso, para esta mesma autora, "começar" a pensar, no sentido artaudiano e blanchotiano, seria pensar disruptivamente, rompendo com uma cadeia naturalizada do pensamento, e, portanto, procurando o impossível, o que não está circunscrito pelo paradigma da probabilidade. Tratar-se-á pois de pensar o impensado ou de dar conta da dimensão de impensável (vazio) do pensamento. Tentará a autora mostrar em que medida tal experiência se aproxima do "pensamento de fora" blanchotiano, evocando desde logo o texto de Michel Foucault.
Reconhece este autor pois a importância do Romantismo, salientando o modo como a literatura teria com ele deixado de ser uma resposta para passar a ser uma questáo ${ }^{13}$. Ter-se-ia então instituído uma nova perspectiva sobre ela, pela qual o primado da representação seria destituído e a escrita passaria a ser entendida simultaneamente como absoluto e fragmento, ou seja, como gesto simultâneo de fundaçáo e de ruptura (lei e contra-lei). Contudo, o fragmento schlegeliano acarretaria, a seu ver, um conjunto de pressupostos que o converteriam antes em aforismo, revelando-se assim, afinal, diferente do fragmentário tal como temos vindo a defendê-lo a partir dos seus textos. São três os problemas enunciados por Blanchot quanto à concepção schlegeliana de fragmento: 1) o facto de Schlegel considerar o fragmento isolado (pois tratar-se-ia de um todo, com o centro em si-mesmo), sem atender ao modo como se estabelecem dinâmicas de relação e de criação de sentido com todos outros fragmentos; 2) o facto de o autor não considerar, pela mesma razão, o intervalo (espera e pausa) entre fragmentos - separação de que depende o princípio rítmico e diferido da obra. Os pontos 1) e 2) resultam na terceira observação: 3) para Blanchot, Schlegel não teria percebido que o fragmento é necessário não porque torna mais difícil a panorâmica do todo, ou mais fracas as relações de unidade, mas porque torna possíveis novas relaçôes que excedem a totalidade e a unidade.

Pelas observações, percebemos que por fragmentário Blanchot compreende, então, mais do que a simples adopção formal do fragmento, a relação (rítmica, constelar) entre vários, múltiplos, fragmentos. A possibilidade de se constituírem relaçóes entre diferentes singularidades - sem com isso anular essas mesmas singularidades - supóe um movimento da diferença no mesmo resultando, desta dinâmica entre a continuidade/descontinuidade, organização/desorganização na obra, a criação de novas possibilidades de sentido, bem como, a evocação do excesso, o resto, no domínio da linguagem - a que poderíamos ainda chamar o "impensado"14 ou o "fora". A fragmentariedade resultaria pois da falha e do excesso (a força, a desmesura) da linguagem e da obra, irredutíveis que são à ordem do discurso e aos cânones.

No número 11 da revista Lignes, número especial no qual é publicado o dossiê de La Revue Internationale ${ }^{15}$, surge claramente indicada a diferença entre fragmentos, salientando o autor, no que diz respeito à literatura, o quarto ponto que identifica:

On peut dire en simplifiant qu'il y a quatre sortes de fragments: 1) Le fragment qui n'est qu'un moment dialectique d'un plus vaste ensemble. - 2) La forme aphoristique, concentrée, obscurément violente, qui à titre de fragment est déjà complète. L'aphorisme, c'est étymologiquement l'horizon, un horizon qui borne et qui n'ouvre pas. - 3) Le 
fragment lié à la mobilité de la recherche, à la pensée voyageuse qui s'accomplit par affirmations séparées et exigeant la séparation (Nietzsche). -4) Enfin une littérature de fragment qui se situe hors du tout, soit parce qu'elle suppose que le tout est déjà réalisé (toute littérature est une littérature de fin des temps), soit parce qu'à côté des formes de langage où se construit et se parle le tout, parole du savoir, du travail et du salut, elle pressent une toute autre parole libérant la pensée d'être seulement pensée en vue de l'unité, autrement dit exigeant une discontinuité essentielle. En ce sens, toute littérature est le fragment, qu'elle soit brève ou infinie, à condition qu' elle dégage un espace de langage où chaque moment aurait pour sens et pour fonction de rendre indéterminés tous les autres ou bien (c'est l'autre face) où est en jeu quelque affirmation irréductible à tout processus unificateur. ${ }^{16}$

Do excerto citado, podemos extrair uma série de conclusóes importantes. Antes de mais, cada obra literária é fragmentária uma vez que, na sua condição de exemplo, indiciando o todo - a literatura -, simultaneamente o abala ou desestabiliza. Um texto literário (apenas assim entendido se considerado um conjunto de protocolos), afirmação do único e do singular, na exacta medida em que determina (e desfaz, como vimos) a sua própria lei, põe sempre em causa a literatura enquanto instituição, lei, corpus, ou mesmo género, e desloca as suas balizas. Trata-se de uma "literatura do fim dos tempos" porque sempre do e no limite agindo como sua problematização e reconfiguração ${ }^{17}$. Contudo, no excerto que destacámos encontra-se sobretudo patente a ideia segundo a qual haveria uma escrita (e forçosamente uma leitura, acrescentaríamos nós) da interrupção, porquanto nela se implicasse um pensamento não sujeito à lógica do trabalho ou do saber, isto é, ao condicionamento da finalidade, que poria, assim, em causa a própria possibilidade de desenvolvimento (também ele discursivo) à luz do princípio da eficiência. A escrita não se restringiria então à noção de unidade, sequer à unidade do livro, nem tão pouco estaria refém de uma consciência intencional - o que a remeteria novamente ao movimento consequente visando certos resultados. A interrupção da uniformidade significa antes a disponibilidade para o jogo, a constituição de relaçóes, mais ou menos fortuitas, entre elementos singulares, garantindo pois a multiplicidade e, para além disso, a mobilidade, a circulação. Consequentemente, o fragmentário interrompe movimentos de totalização e inviabiliza várias perspectivas, algumas das quais pretendem desvendar nos textos unidades fechadas de sentido. Entre várias concepções perturbadas pelo fragmentário poderíamos elencar estas quantas: o gesto pelo qual se póe a tónica da análise na estrutura dos textos (modus operandi dos estruturalistas); a crença no contexto segundo a lógica da causalidade; a consideração da linguagem enquanto mero meio de comunica-
15. É por volta de $1960 / 61$ que surge a Blanchot a ideia de uma revista internacional a ser constituída por textos críticos, filosóficos e literários. O plano passava também por reunir alguns dos nomes mais proeminentes na Europa, bem como nos Estados Unidos e na América do Sul. Blanchot contactou o romancista italiano Elio Vittorini, o poeta alemão Hans Magnus Enzensberger, Italo Calvino, Günter Grass, entre outros. La Revue Internacional nunca viria a ser concretizada, embora Blanchot tenha trabalhado no projecto durante quatro anos. O dossiê publicado na revista Lignes resulta desses anos de pesquisa e de trabalho.

16. BLANCHOT, Maurice.

"Memorandum sur le cours des choses", 1990, p. 187-188.

17. Quanto a isto, na medida em que há como base comum uma concepção de "universo das obras", é de sublinhar os textos de Blanchot em L'Amitié sobre o "museu imaginário" de Malraux: "Le Musée, l'Art et le Temps" e "Le mal du Musée". Neles, Blanchot sublinha que a ideia de colecção implicada na noção de museu - a exigência da representatividade pela acumulação de exemplos - apenas pode dar conta da impossibilidade de uma totalidade harmoniosa, já que cada um dos exempla se afirma como singularidade irredutível ao todo (fictício) da colecção - infinita e indeterminada, na medida em que será sempre possível acrescentar um novo elemento. 
18. BLANCHOT, Maurice. Le Pas au-delà, 2008, p. 74-75. ção; a convicção de que a narrativa segue a ordem da sucessão ou resulta da síntese entre as partes.

Não havendo dele uma definição clara, porque não se trata de um conceito de que pudéssemos dispor, o fragmentário é, mais do que um efeito, um acontecer na escrita/leitura, relacionando-se com o "neutro" enquanto processo de inscrição e de auto-apagamento (veremos adiante em que poderá consistir tal movimento, quando nos debruçarmos, mais especificamente, sobre a leitura). A dificuldade em dar conta do fragmentário prende-se pois com o facto de não ser algo que se manifeste firmemente como característica identificável na modalidade estrutural dos textos, como forma, tema ou modo. Embora não identificável, é todavia possível indicar o fragmentário, assinalando algumas particularidades dos textos aquando do exercício de leitura. Veja-se como Blanchot disso nos dá algumas pistas:

- Personnages: ils sont en position de personnage, et pourtant ce sont des points de singularité (des feux de lieu au locaux), immobiles, quoique le parcours d'un mouvement dans un espace raréfié, en ce sens qu'il ne peut presque rien s'y passer, se trace des uns aux autres, parcours multiple par lequel, fixes, ils ne cessent de s'échanger et, identiques, de changer. Espace raréfier que l'effet de rareté tend à rendre infini jusqu'à la limite qui ne le borne pas. L'effet de rareté est propre au fragmentaire. La mort ici, loin de faire œuvre, a toujours déjà fait son œuvre : désoeuvrement mortel. Par là, l'écriture selon le fragmentaire, ayant toujours lieu où il y a lieu de mourir et donc comme après la mort perpétuelle, met en scène, sur un fond d'absence, des semblants de phrases, des restes de langage, des imitations de pensée, des simulations d'être. Mensonge que ne soutient aucun vrai, oubli qui ne suppose rien d'oublié et qui est détaché de toute mémoire : sans certitude, jamais.

Le désir détourné en désir. Comme un heurt de clartés. ${ }^{18}$

Implicando a escrita fragmentária a deslocação de diversos elementos textuais pela criação de relaçôes múltiplas, e anulando assim, de imediato, a submissão da obra a uma unidade ou identidade tutelar, compreende-se em que medida ela pode corresponder a uma desestruturação ou desregulamento em termos temporais: já não admite de forma estrita a sequencialidade ou a linearidade $\mathrm{e}$, em seu lugar, institui uma temporalidade (espacial) marcada pelo salto, pela ruptura, pelo retorno, enfim, pela diferença.

Posto que a descontinuidade não se restringe ao nem depende do fragmento, tal como Blanchot expóe no texto de $\mathrm{La}$ Revue Internacional, publicado na revista Lignes no11, em 1990, e que por isso não cabe stricto senso à problemática da modernidade - embora a ela se possa assimilar -, será necessário averiguar os modos como a interrupção é, mais do que uma possibilidade, uma exigência dos textos. Diremos, então, que a aber- 
tura implicada nesta ideia de fragmentário (o descentramento, "diferança", a não-presença a si, o impensado, o fora) acontece a par de uma necessária desvinculação (ruptura) da escrita relativamente àqueles que aparentemente seriam os seus contextos e pretextos (o conjunto de presenças, como diria Derrida, que organizam o seu momento de inscrição). Associa-se pois a mobilidade textual a um certo tipo de desamparo - como se os textos fossem cartas (duplamente) perdidas -, uma fragilidade que, afinal, corresponderia à sua força, enfim, uma potência do vazio, se assim podemos dizer. A citação, enquanto modo particular de "iterabilidade", seria disso o indício mais significativo, porque expóe essa mobilidade da linguagem - conforme veremos, a leitura, elemento determinante para a constituição do espaço literário, pressupóe desde logo o jogo entre tempos e, portanto, nessa medida, o fragmentário.

Importa igualmente sublinhar o seguinte: a hipótese de a escrita se encontrar associada a modos de interrupção que precisamente resultam nessa abertura, que até atinge uma dimensão temporal, não é uma intuição nova e durante muito tempo se encontrou vinculada aos argumentos pelos quais se defendia a oposição (estreita) entre o signo inscrito e o signo fonético. Há uma perplexidade antiga, remontando pelo menos a Platáo, relativamente à qualidade disruptiva e múltipla da escrita, devedora de uma ideia ainda hoje mais ou menos difundida segundo a qual se pensa a inscrição em suporte (específica ao gesto de escrever) em tensa relação/oposição com a fala, ou seja, com a exigência da presença do falante aquando do acto elocutório. No passo que se segue, pretendemos assinalar o modo como a desconfiança de Sócrates, pensada por Blanchot, diz respeito à intuição de um vazio e de uma desmesura que potenciam afinal a multiplicidade e o jogo, ou seja, um certo tipo de desregulamento da língua.

\section{Diferimento e estranheza}

No Fedro de Platão, a suposição de que a escrita é uma espécie de fala imperfeita resulta na sua mais alta condenação. Sócrates apresenta dois argumentos centrais que justificam a desaprovação da escrita. Pelo primeiro defenderá que esta, servindo apenas para efeitos de rememoração, é nociva à manutenção da memória, pois desobriga ao exercício mental que aquela implicaria; enquanto 'morta', corresponderia entáo a uma palavra do esquecimento. Através do segundo observa que, estando envolvida na escrita a possibilidade da não presença quer do destinador quer do destinatário, abre-se o flanco aos mais diversos desvios. 
19. As considerações tecidas em torno da tensão entre fala e escrita são decisivas para pensar a literatura. Elas expõem os embaraços suscitados pelos textos ou, melhor dizendo, pela linguagem quando posta em relevo, esses que os ligam à ficção não porque se oponham à verdade, mas porque suspendem a exigência da presença pressuposta na fala, de onde a possibilidade da citação e a indecidibilidade entre uso e menção, constativo e performativo, próprio e impróprio, isto é, da criação de idiomas. A ideia de que a literatura é ficção não depende nem decorre imediatamente do facto de quem escreve pretender construir uma ficção, mas surge sobretudo devido à suspensão da relação entre destinador/ destinatário, pela deslocação aí implicada e pelo em-aberto que suscita.

20. Seguiremos a edição da Gallimard de 2002, da coletânea Une Voix vennu d'ailleurs.
Ninguém responderá pelo texto, ninguém se responsabilizará pelo dito, deixando campo aberto ao equívoco, à multiplicidade, ao acaso. O problema reside essencialmente no facto de a marca não garantir a clareza da significação, e atraiçoar assim a intenção comunicativa dos sujeitos. Mantém-se na sua potência de objectivação como letra muda, indisponível, secreta.

$\mathrm{Na}$ escrita está pois em causa a deslocação de uma palavra sem origem nem fim adequados. É a irresponsabilidade dessa palavra sem destinação, bem como a irresponsabilidade patente no gesto de abandono do escritor, que aparecem a Sócrates como um escândalo. Quem fala deve ser responsável pelo que diz, para tornar transparente o dito, desfazendo dúvidas, se solicitado, assim evitando enganos. Com a escrita introduz-se precisamente a possibilidade (irresponsável) do equívoco, do desvio e da incerteza. Ela ocasionaria a interrupção da eficácia discursiva, tal como entendida em Fedro (a enunciação inequívoca e infalível de conteúdos previamente definidos, bem como a sua adequada recepção), e isso por desde logo implicar o desfasamento temporal, o intervalo, o silêncio e a ambiguidade. A ironia talvez esteja no facto de Platáo supostamente ter passado para escrito (citado) - de memória - este mesmo diálogo, admitindo afinal a cesura que Sócrates tanto temia ${ }^{19}$.

Blanchot indagará as consideraçóes platónicas sobre a palavra escrita num texto intitulado "La Bête de Lascaux", primeiramente publicado, segundo uma nota do autor, em 1958, e novamente reeditado em $1982^{20}$. Este texto é precedido por um poema de René Char, autor que inspira a Blanchot algumas ideias sobre o fragmento, "La Bête Innommable". O cruzamento entre as pinturas de Lascaux, Platão e René Char, temporalmente tão distantes, parece inusitado. Como pode ser ele pensado?

Em primeiro lugar, tomemos em linha de conta a publicação, em 1955, de La Peinture préhistorique. Lascaux, ou la naissance de l'art, de Georges Bataille, ensaio no qual é desdobrada uma série de consideraçóes sobre o tempo do nascimento da arte. Importa considerar as ideias aí ensaiadas, já que elas encontrarão ressonância no texto de Blanchot. Uma das mais interessantes diz respeito à relação tensa e necessária entre o homem do utensílio, da técnica e do trabalho, e o homem do jogo. Para Bataille, é na medida em que o homem (Homo faber, Neandertal) inventa o utensílio para fins uteis à sua sobrevivência que pode, depois (Homo sapiens), libertá-lo do campo estrito da actividade utilitária. Desvinculando o utensílio (a técnica) da sua função de eficácia, o homem poderá dedicar-se a actividades não orientadas pela necessidade e pelo proveito mas sim pelo desejo e pela dissipação. $\mathrm{O}$ nascimento da arte diria entáo respeito a coisas tais como o jogo e a festa, a celebração e o riso, e implicaria a transgressão do trabalho e das leis, isto é, dos interditos (leis que organizam e que contêm as forças desreguladas da vida e da 
natureza - daí relacionarem-se com a sexualidade e a morte - de modo a manterem o mundo ordenado do trabalho ao abrigo das forças brutas). Ainda que não recuse em absoluto a existência da dimensão mágica, Bataille crê que confinar as pinturas de Lascaux a tal funcionalidade é, em última análise, uma simplificação. Convocará a célebre figura do "Unicórnio" para destacar a componente imaginária, irredutível à explicação de que tais pinturas servissem a vontade humana de acção directa no mundo natural (auxiliando as tarefas da caça e da recolecção, por exemplo). Dirá ainda que o Homo sapiens se distingue dos seus percussores menos pelo conhecimento do que pela arte. Bataille vê pois na arte a gratuitidade, a alegria, enfim, o jogo. O tempo do seu nascimento corresponde precisamente ao momento de interrupção com a finalidade ou com a utilidade, portanto, ela surge desse vazio activo e enérgico pelo qual se abre à possibilidade (aí encontrando-se congregadas a força de memória e a força imaginante).

Ora, de algum modo, é precisamente a intuição de uma dimensão de jogo e de acaso - ruptura com a seriedade da palavra consequente e eficiente - que levará Sócrates, na obra de Platão que vimos explorando, a declarar a sua desconfiança relativamente à palavra escrita. Esta resulta do desenvolvimento de uma técnica, portanto de um artifício, a inscrição, pela qual se abre a distância, o intervalo, e se dá uma outra temporalidade e o saber impessoal - palavra morta, palavra do esquecimento. Linguagem estranha, assinala Sócrates, pela qual alguém fala e no entanto ninguém fala, presença ou voz da ausência; uma palavra dizendo sempre o mesmo, repetindo-se, sem que haja garantia sobre o seu sentido - pois não há homem que garanta o seu valor de verdade -, sem que ela mesma saiba o que diz, incapaz de responder ou de se defender se indagada. Tal palavra é, assim o entende, aparência daquilo que diria coisas verdadeiras, mas vazia: correspondendo à impossibilidade de falar e sem nada que a sustente. Em súmula, é palavra injustificada, sem fundamento. Conforme comenta Blanchot:

C'est pourquoi, Platon et Socrate, dans le même passage, se hâtent de faire de l'écriture comme de l'art un divertissement où le sérieux n'est pas compromis, qu'on réservera aux heures de récréation, semblables à ces jardins en miniature formés artificiellement dans des corbeilles pour l'ornement des fêtes et appelés jardins d'Adonis. Le discours écrit, le "volume”, ne sera donc qu'un "jardin en lettres d'écriture", capable tout au plus de commémorer les œuvres ou les événements du savoir, sans avoir nulle part au travail de leur découverte. Et l'on voit ici Socrate rapprocher à nouveau l'écriture du sacré en la rapprochant de la célébration qui interrompt l'activité laborieuse de l'homme voué au vrai pour l'introduire dans le temps de la fête. Seulement, l'an- 
21. BLANCHOT, Maurice. "La bête de Lascaux", 2002, p. 54-55.

22. Idem. L'Écriture du desastre, 1980 , p. 25.

23. Idem. "La bête de Lascaux", 2002, p. 56.

24. Vale a pena repensar o texto de Derrida sobre o "dom" à luz das considerações acima expostas, pois do que se trata em Donner le temps. Essai sur le don I - La fausse monnaie, de 1991, senão da resistência à lógica da equivalência? O "dom" surge ao filósofo como aquilo que não faz parte do círculo da troca. É dentro da mesma ordem de ideias que o dom será pensado na sua relação com a escrita e com a literatura. tique sauvagerie prophétique du chêne n'est plus qu'un aimable jardin en miniature, de même que la fête n'est plus qu'un divertissement. ${ }^{21}$

Porque a palavra escrita aparece como essencialmente por vir, isto é, sem fundamento anterior, Sócrates reconhecerá a sua relação com o jogo, pretendendo por isso reduzi-la a mera actividade de distracçáo, circunscrita aos tempos livres, ou seja, o tempo que sobraria, depois do tempo do trabalho, da produção, da obra (uma distribuição segundo uma lógica economicista, a que nem a temporalidade escapa). Destacam-se duas questóes: uma vez que perturba a lógica de uma comunicação eficiente e sem resto, o texto, fazendo-se campo de forças constituído por constelações, ritmos, cadências, tonalidades, relações diversas, demitindo a totalidade e o discurso monológico da sua soberania, abre ao por vir; sem constituir a sua negação, a palavra e o seu sem fundamento interrompem o princípio da razão, assim como uma concepção restrita de memória e do tempo. A possibilidade do jogo embaraça, pois, a lógica da competência e do progresso. Leia-se, para reforçar este argumento, um dos fragmentos de L'Écriture du desastre, atentando já na relação estreita entre "desastre" e "fragmentário":

- Au-delà du sérieux, il y a le jeu, mais au-delà du jeu, cherchant ce qui se déjoue : le gratuit, auquel on ne peut se dérober, le casuel sous lequel je tombe, toujours déjà tombé. Il passe des jours et des nuits dans le silence. C'est la parole, cela. ${ }^{22}$

A escrita e a palavra sagrada (também ela alvo das desconfianças de Sócrates) aproximar-se-iam na exacta medida em que ambas não encontram justificação para lá de si mesmas e, sendo mudas, nada dizem, indicam. Neste ponto, o pensamento de Heraclito, admirado quer por Blanchot quer por Char, torna-se essencial e vem ao de cima:

Héraclite y répond en quelque sorte à Socrate en reconnaissant, dans ce qui fait de la parole impersonnelle de l'oracle un danger et un scandale, l'autorité véritable du langage : “ Le Seigneur dont l'oracle est à Delphes, n'exprime ni dissimule rien, mais indique." Le terme "indique" fait ici retour à sa force d'image et il fait du mot le doigt silencieusement orienté, l'" index dont l'ongle est arrachê" et qui, ne disant rien, ne cachant rien, ouvre l'espace, l'ouvre à qui s'ouvre à cette venue. $^{23}$

Na base da rejeição de Sócrates está o anseio pela palavra adequada à troca. Uma palavra de câmbio ${ }^{24}$, não apenas na medida em que haveria alguém responsável (uma presença) que a pudesse explicar - como se diz na gíria, que "a trocasse por miúdos" -, como também, na medida em que esta seria plena por- 
que sem ambiguidade, podendo assim estabelecer-se uma lógica da equivalência. $\mathrm{O}$ carácter profético da palavra na qual fala a origem (assim declara Blanchot - origem essa que podemos relacionar com o "fora", e portanto uma origem por vir) não é confundível com a palavra que dita o futuro. Esta palavra náo fala ("não exprime nem dissimula nada"; não se sustenta de nenhuma verdade já estabelecida ou evento decorrido), apenas indicia, abre. Trata-se de uma palavra que começa. "Il (langage) indique l'avenir, parce qu'il ne parle pas encore, langage du futur" ${ }^{25}$. Nunca se escuta totalmente num "agora", isto é, no presente (porque não se confina ao presente), tal como acontece com a palavra da Sibila, "langage qui ouvre la durée, qui déchire et qui débute"26. Há o movimento de "(re-)começo" (commencement). Explica-nos Blanchot: "en cela qu'il est lui-même comme un langage futur, qui toujours se devance, n'ayant son sens et sa légitimité qu'en avant de soi, c'est-à-dire foncièrement injustifitié" 27 .

Retomando tais considerações e assinalando uma afinidade entre Char e Heraclito, Blanchot caracterizará a poesia do primeiro como "canto do pressentimento", uma poesia cujo fulgor acontece por via de um movimento simultâneo de retirada e de promessa, de ruptura e, por isso mesmo, de começo e de abertura porque arrancada do seu presente. Contrariamente à palavra profética que se torna autoritária e, assim, compacta, integral, os poemas de Char dar-se-iam como coisa "pulverizada": "oeuvre tendue mais patiente, orageuse et plane, énergique, concentrant en elle, dans la brièveté explosive de l'instant, une puissance d'image et d'affirmation qui "pulvérise" le poème et pourtant gardant la lenteur, la continuité et l'entente de l'ininterrompu" 28 .

Blanchot parece pois apontar para a relaçáo entre a exigência fragmentária e o por vir. É na medida em que a obra transporta consigo o princípio da sua própria dissolução - a partir da contradição, da incongruência, do silêncio, da mudez, a presença da ausência, da não garantia, do jogo, da interrupção -, o désoeuvrement, que se abre o espaço múltiplo e o movimento da repetição e da diferença - a deslocação sem negação. Em L'Entretien Infini, num texto incidindo principalmente sobre o "Poema pulverizado" (escrito entre 1945 e 1947, segundo a indicação das obras completas publicadas pela Gallimard), podemos ler aquilo que aproxima o fragmentário, a deslocação - que supõe a interrupção - e a palavra por vir:

Parole de fragment: il est difficile de s'approcher de ce mot. "Fragment", un nom, mais ayant la force d'un verbe, cependant absent: brisure, brisées sans débris, l'interruption comme parole quand l'arrêt de l'intermittence n'arrête pas le devenir, mais au contraire le provoque dans la rupture qui lui appartient. Qui dit fragment ne doit pas seulement dire fragmentation d'une réalité déjà existante, ni moment d'un ensemble encore à venir. Cela est difficile à considé-
25. BLANCHOT, Maurice. "La bête de Lascaux", 2002, p. 57.

26. Ibidem, p. 57.

27. Ibidem, p. 57.

28. Ibidem, p. 63. 
29. Idem. L'Entretien Infini, 2009, p. $451-452$. rer par suite de cette nécessité de la compréhension selon laquelle il n'y aurait connaissance que du tout, de même que la vue est toujours vue d'ensemble : selon cette compréhension, il faudrait que, là où il y a fragment, il ya ait désignation sous-entendue de quelque chose d'entier qui le fut antérieurement ou le sera postérieurement - le doigt coupé renvoie à la main, comme l'atome premier préfigure et détient l'univers. Notre pensée est ainsi prise entre deux limites, l'imagination de l'intégrité substantielle, l'imagination du devenir dialectique. Mais, dans la violence du fragment et, en particulier, cette violence à laquelle il nous est permis d'accéder par René Char, un tout autre rapport nous est donné, au moins comme une promesse et comme une tâche. "La réalité sans l'énergie disloquante de la poésie, qu'est-ce?"

Il faut essayer de reconnaître à l'"éclatement" ou à la "dislocation" une valeur qui ne soit pas de négation. ${ }^{29}$

Enuncia-se pois o que importa no fragmentário: a força deslocante. Esta força relaciona-se com a diferença (différance), uma diferença que não seja negativa: "reconnaître à l'" éclatement" ou à la "dislocation" une valeur qui ne soit pas de négation". A força deslocante relaciona-se com o por vir, já que enunciando-a sugere-se que a poesia (texto, palavra) acontece advindo como diferido. Tal suposição, afinal, impele-nos a considerar também o gesto de envio ou de endereçamento e, portanto, o carácter testamentário e testemunhal dos textos (como cartas perdidas) dirigidos aos que virão, a comunidade aberta de leitores, a comunidade "inconfessável". É pesando este advir que dedicaremos as próximas páginas à questão da leitura, cuja pertinência se torna mais acentuada se pensarmos na escrita como leitura e na leitura como escrita, como recomeços pois.

\section{Escrita/leitura}

Como pedra de toque para a meditação sobre o exercício de leitura, considere-se na sua totalidade o seguinte fragmento de Le Pas au-delà:

- Le fragmentaire n'étant pas expérience, n'étant pas forme ou sujet d'écriture, n'étant pas un autre ordre ou regard de l'ordre du livre, même comme passage à un désordre : cependant, obscure exigence sous l'attrait de laquelle l'espace d'écrire donne lieu à des marques ou points de singularité par où passent des parcours multiple (irréguliers) qui les font disparaître comme uniques tout en les maintenant en position de singularité, de sorte qu'une multiplicité quasi infinie de traverses peut s'y répéter, sans que la répétition 
en supprime la marque de singularité ni dissolve celle-ci en identité. C'est comme si cet espace se donnait comme corrélatif ou supplémentaire ou même secondaire (en ce sens inessentiel), tout en repoussant, en faisant éclater ce dont il semblerait être le corrélat ou le supplément, secondaire donc sans prime. D'où le travail d'obscurité que le recommencement conduit et conduit toujours plus obscurément. Lecture, écriture s'échangent à la faveur de ce "corrélat" contre lequel elles luttent pour l'empêcher, luttant aussi contre le pouvoir en elles de le produire ou de le restaurer.

Il ne s'agit pas de substituer lecture à l'écriture ou de privilégier l'une contre l'autre, mais de les redoubler pour que la loi de l'une soit l'interdit de l'autre. Par le fragmentaire, écrire, lire changent de fonction. Aussi longtemps qu'écrire, c'est écrire un livre, ce livre est soit achevé ou maintenu par la lecture, soit menacé par elle qui tend à le réduire ou à l'altérer, bien qu'il soit toujours et encore par essence supposé indemne dans sa totalité irréelle (l'œuvre, le chef-d'œuvre) qu'il a une fois pour toutes instituée. Mais si, écrire, c'est disposer des marques de singularité (fragments) à partir desquelles des parcours peuvent s'indiquer sans les réunir ni les joindre, mais comme leur écartement - écartement d'espace dont nous ne connaissons que l'écart : l'écart, sans savoir de quoi il s'écarte -, il y a toujours risque pour que la lecture, au lieu d'animer la multiplicité des parcours transversaux, reconstitue à partir d'eux une totalité nouvelle ou, pis, cherche dans le monde de la présence et du sens à quelle réalité ou chose à compléter correspondent les vides de cet espace qui se donne pour complémentaire, mais complémentaire de rien. ${ }^{30}$

Embora compreendendo a indispensabilidade da leitura, Blanchot identifica dois perigos que esta pode acarretar - perigos na medida em que se traduziriam na anulação da multiplicidade. São eles a constituição de uma totalidade ou o preenchimento dos vazios com correspondências encontradas no "mundo da presença ou do sentido". Analisámos há pouco o argumento de Bataille, tal como explícito em La Peinture préhistorique. Lascaux, ou la naissance de l'art, segundo o qual ao tempo do nascimento da arte corresponderia o momento de interrupção com a ordem do mundo (as leis, o trabalho, a sobrevivência), dando-se como espaço despojado, livre. Não estará precisamente, no trecho citado, Blanchot a alertar para o facto de certo tipo de leitura anular esse despojamento, reconduzindo a obra ao domínio do reconhecível e, por conseguinte, tornando-a manejável e apropriável? A leitura deve deixar a obra/texto ser o que é, diz Blanchot em L'Espace Littéraire, logo, a leitura deve sobretudo ser acolhimento. Mas se a obra, mantendo-se aparentemente incólume, é fragmentariedade e multiplicidade, como então ler acolhendo a sua dispersão?

Derrida pode lançar alguma luz sobre o nosso problema. Em "Deux mots pour Joyce" 31 , o filósofo mostra como cada
30. BLANCHOT, Maurice. Le Pas au-delà, 2008, p. 73-74.

31. Discurso proferido no Centro George Pompidou, em 1982. Foi publicado mais tarde em Ulysse gramophone em 1987, edição que seguiremos. 
32. SAN-PAYO, Patrícia. Blanchot: a possibilidade da literatura, 2003.

33. Não seria totalmente descabido aproximarmos estas considerações ao que Benjamin definiu como "aura" e o "vestígio" nas obras de arte, já que neles se joga precisamente esta ideia do que sendo próximo se afasta, exigindo um trabalho da paciência. texto afirma a singularidade do seu idioma e, portanto, a sua insubstituibilidade, bem como a multiplicidade das línguas que o compóem. Caso paradigmático e radical disso seria Ulysses de James Joyce, texto sobre o qual particularmente se debruça, cuja singularidade reside, embora náo exclusivamente, na complexa intersecção e combinação de linguagens e mesmo de formas. Desde logo esta obra engendra a refracção que a torna ilegível, e nenhuma competência ou saber permitirá aceder ao texto no seu todo. $\mathrm{O}$ aquiescimento da obra é ambíguo, pois, se convida à leitura, simultaneamente impede-a, conservando um resto inexorável. A obra solicita o esforço de tradução infinito, destinado contudo ao fracasso. Cada leitura seria, assim, a experiência do fazer e desfazer, escrita e apagamento, assinatura e contra-assinatura (e recordemos o que havíamos dito acerca do neutro enquanto movimento de inscrição e apagamento). Aparece ela assim como uma espécie de tarefa de Sísifo: o texto solicita um exercício de leitura, mas mantém-se sempre ilegível; a obra exige as leituras mas nunca é, a bem dizer, lida. Paradoxalmente, a leitura não chega a começar e, todavia, náo acaba. Dando conta da estranha condiçáo da leitura, Derrida aproxima-se de Blanchot. Como esclarece Patrícia San-Payo ${ }^{32}$, para Blanchot, o sentido na escrita/leitura relaciona-se com o movimento de uma exegese infinita, correspondendo esta a uma multiplicidade, leituras de leituras, à qual o leitor náo pode aceder no seu todo. Podemos dizer que o texto se dá então como próximo, familiar e, simultaneamente, afastado, estranho ${ }^{33}$. Talvez encontremos aqui uma possível resposta para a pergunta acima esboçada. A leitura acolhe quando respeita a alteridade e a irredutibilidade do texto, não pretendendo substituí-lo, explicá-lo, sabendo-se de antemão inexequível.

Porém, a leitura é também recomeço, reescrita. Conforme já havíamos adiantado, o intervalo entre escrita e leitura constitui o espaço literário - espaço de uma errância em torno de um centro descentrado -, estando nele em causa uma experiência da obra enquanto interrupção (désoeuvrement) e a possibilidade de um "recomeçado recomeço". A leitura é assim a marca de uma específica temporalidade do texto; essa temporalidade é a de um encontro em que a obra sendo precisamente encontro (entre a letra e o leitor) é no encontro (se faz nessa leitura). Neste estabelece-se a tensão relacional entre a infidelidade e a preservação ou entre a invenção e o rigor na atenção à letra. Não sendo pois práticas absolutamente distintas, a escrita e a leitura constituem momentos de uma afirmaçáo necessariamente plural que conduz à problematização do tempo e do espaço literário. Ou seja, no diferimento em jogo no intervalo entre escrita e leitura acontece a cisáo do presente contextual quer de uma quer de outra, abrindo-se um espaço-tempo anómalo.

Tal intervalo é o que possibilita a comunicação ou comu- 
nicabilidade do texto (não confundível com a comunicação em termos mais restritos), e implica repensar o tema das relaçóes pelas quais estas se estabelecem. O pensamento de Blanchot, na esteira do de Lévinas, assinala a incomensurabilidade de qualquer relação e mostra como todas elas são dissimétricas. Havendo nelas a necessidade da procura e da interrogação, elas supóem a repetição e o desvio, isto é, a exigência de descontinuidade ${ }^{34}$. A interrogação (escrita/leitura?) em Blanchot não se confunde por isso com a elaboração de uma pergunta sobre alguma coisa ou sobre um tema determinado, pela qual se esperaria uma resposta que viesse satisfazer a nossa curiosidade e preencher a lacuna dessa ignorância ou desse náo saber. A interrogaçáo blanchotiana é aquilo a que o autor chama "a questão essencial" ou "a questão mais profunda". Trata-se do ímpeto indagador mas sem objecto, um desejo pelo desejo, um pensar movido pelo desconhecido enquanto desconhecido. Lembremo-nos do desejo de Orfeu pela sombra ou pela dimensão de segredo de Eurídice, a que ainda há pouco aludimos, e percebamos nele o exemplo desse impulso desejante pela obscuridade enquanto obscuridade, a força ou a potência de questionamento, enfim, do pensamento. Daí que a "questáo" abra à possibilidade de um encontro desencontrado com o outro. Tal desejo desfaz a estabilidade de um diálogo, de uma escrita/leitura na dependência de alguns dos mais convencionais paradigmas da comunicação: o movimento progressivo, a necessidade ou o fim a atingir, seja ele informativo ou outro, por exemplo. Haverá, sob o signo do desejo, um movimento em direcção ao outro mas segundo o que neste é alteridade, desconhecido, e que não é subsumível seja pela compreensão seja pelo reconhecimento. Estaria isso também em causa na leitura.

L'une des questions qui se posent au langage de la recherche est donc liée à cette exigence d'une discontinuité. Comment parler de telle sorte que la parole soit essentiellement plurielle? Comment peut s'affirmer la recherche d'une parole plurielle, fondée non plus sur l'égalité et l'inégalité, non plus sur la prédominance et la subordination, non pas sur la mutualité réciproque, mais sur la dissymétrie et l'irréversibilité, de telle manière que, entre deux paroles, un rapport d'infinité soit toujours impliqué comme le mouvement de la signification même? Ou bien encore comment écrire de telle sorte que la continuité du mouvement de l'écriture puisse laisser intervenir fondamentalement l'interruption comme sens et la rupture comme forme? ${ }^{35}$

O que está em jogo não é a interrupção, a respiração necessária ao discurso e ao diálogo, é antes a descontinuidade que abala os processos integradores e homogeneizantes da compreensão e, por conseguinte, admite a emergência da palavra plural. Tratar-se-á também de perceber que o discurso literário caracte-
34. Daí que Blanchot tenha pensado o diálogo e o tenha abalado nos seus fundamentos dialógicos. L'Entretien Infini, cujo título é já uma explicitação daquilo que Blanchot entende ser o encontro entre falantesfalantes/leitores-textos, é o que com maior acuidade explicita a problemática, num texto intitulado "Le rapport du troisième genre - Homme sans horizon". Nele encontramos identificados três géneros de relações: uma primeira em que impera a lei do mesmo - o homem quer a unidade a todo o custo, ainda que constatando a separação; por diversos meios procurará a dissolução da diferença (a adequação, a identificação, a mediação serão algumas das suas estratégias), bem como apelará para o todo, e a verdade será o cimento da unidade. Está em causa uma metodologia de pendor dialéctico, pela qual se tende para uma unidade construída (A tende para B). No segundo caso de relação está em causa um processo fusional de redução ao mesmo. Contrariamente ao primeiro, não há um momento de perturbação. Trata-se de uma ideia de comunicação imediata (AB é uma unidade, formam o um: o mesmo devir; o mesmo tornar-se idêntico). A última relação descrita por Blanchot é a do múltiplo que supõe o desvio e já não a unidade. O que nela está em jogo é a deslocação: tornar-se sempre outro, devir outro.

35. BLANCHOT, Maurice. L'Entretien Infini, 2009, p. 9. 
riza-se pela pluralidade de linguagens e pelo carácter de afirmação de cada uma delas, como vimos a partir da leitura de Derrida sobre Joyce, e portanto impede uma leitura fluida, dando-se ao leitor na descontinuidade. A criação de sentido implicada na escrita/leitura (enquanto recomeços) obstaculiza a suposição de que as obras trariam consigo uma resposta, muito menos, uma única. E é nessa medida que importa perspectivar a abertura, o pensamento do fora, a alegre metamorfose que os textos testemunham - dádiva aos que virão. 


\section{Referências}

BARRENTO, João. O Género intranquilo, anatomia do ensaio e do fragmento. Lisboa: Assírio \& Alvim, 2010.

BATAILLE, George. La peinture préhistorique. Lascaux, ou la naissance de l'art. Génova: Éd. D’Art Albert Skira, 1955.

BLANCHOT, Maurice. Le Livre à venir. Paris: Gallimard, 1999

"La bête de Lascaux". Une Voix venue d'ailleurs. Paris:

Gallimard, 2002

. L'Espace Littéraire. Paris : Gallimard, 2005

. Écriture du désastre. Paris : Gallimard, 2006

. Le Pas au-delà. Paris: Gallimard, 2008.

. L'Entretien Infini. Paris: Gallimard, 2009.

. "Guerre et littérature". In :

L'Amitié. Paris :

Gallimard, 2010.

. "Memorandum sur le cours des choses". Lignes, n.11,

p. $187-188,1990$.

BENJAMIN, Walter. O Conceito de Crítica de Arte no

Romantismo Alemão. São Paulo: Iluminuras/ EDUSP, 1993.

BOWIE, Andrew. From Romanticism to critical theory. The philosophy of german literary theory. London / New York:

Routledge, 1997.

DERRIDA, Jacques. Donner le temps I. La fausse monnaie.

Paris: Galilée, 1991.

. Ulysse Gramophone. Paris: Galilée, 1987.

GUERREIRO, Fernando. "Notas sobre este livro". In: SAN-

PAYO, Patrícia. Blanchot, a possibilidade da literatura. Lisboa:

Vendaval, 2003, p. 9-15.

GILLOCH, Graeme. Walter Benjamin - Critical Constellations. Cambridge: Polity, 2002.

GROSSEMAN, Évelyne. "L'Impensable, la pensée". In:

BIDENT, Christophe; VILAR, Pierre. Maurice Blanchot. Récits critiques. Tours: Éd. Farrago, 2003, p. 69-76.

HILL, Leslie. Maurice Blanchot and fragmentary writing: a change of epoch. London/ New York: Continuum, 2012. 
HOPPENOT, Éric. "Maurice Blanchot et l'écriture fragmentaire : 'le temps de l'absence de temps'". In : RIPOLL, Ricard (Org.). L'Ecriture fragmentaire : théories et pratiques, Actes du 1er Colloque International du Groupe de Recherche sur les Ecritures Subversives. Barcelona: Éditions Presses Universitaires de Perpignan, 2001.

LACOUE-LABARTHE, Philippe ; NANCY, Jean-Luc (orgs.) L'Absolu littéraire. Théorie de la Littérature du Romantisme allemand. Paris: Seuil, 2010.

LÉVINAS, Emmanuel. Autrement qu'être ou au-delà de l'essence. Dordrecht: Martinus Nijhoff Publishers, 1986.

LOPES, Silvina Rodrigues. Anomalia Poética, Lisboa: Vendaval, 2005.

PLATÃO. Phèdre. Paris: Flammarion, 2004.

SAN-PAYO, Patrícia. Blanchot: a possibilidade da literatura. Lisboa: Vendaval, 2003. 